\title{
RESILIÊNCIA FINANCEIRA GOVERNAMENTAL E ENFRENTAMENTO À COVID-19
}

\section{GOVERNMENT FINANCIAL RESILIENCE AND COPING WITH COVID-19}

\author{
LUCAS CANDEIA MARTINS \\ Professor da Faculdade Escritor Osman da Costa Lins (UNIFACOL) \\ Mestre em Ciências Contábeis - Universidade Federal de Pernambuco (UFPE) \\ Orcid: https://orcid.org/0000-0003-1168-0454 / E-mail: lucas.martins00@live.com \\ Endereço: Rua Pedro Ribeiro, 85 - Bairro Universitário, Vitória de Santo Antão - PE, CEP: 55612-285
}

THIAGO VITOR FERREIRA SOARES

Professor da Universidade Estácio - Faculdade de Alagoas (UNESA/FAL)

Mestre em Ciências Contábeis - Universidade Federal de Pernambuco (UFPE)

Orcid: https://orcid.org/0000-0003-4728-2212 / E-mail: thiagovitor0401@hotmail.com

\section{PAULYANE GOMES DA SILVA}

Graduada em Ciências Contábeis - Faculdade Escritor Osman da Costa Lins (UNIFACOL)

Orcid: https://orcid.org/0000-0002-9550-2403 / E-mail: paulysilva41@gmail.com

\section{AMANDA BRAZ DA SILVA}

Graduada em Ciências Contábeis - Faculdade Escritor Osman da Costa Lins (UNIFACOL) Orcid: https://orcid.org/0000-0003-0518-7540/E-mail: amandabrazsilva@ hotmail.com

Submissão: 15/08/2020. Revisão: 16/11/2020. Aceite: 19/12/2020. Publicação: 29/12/2020. DOI: http://dx.doi.org/10.22277/rgo.v14i1.5742

\section{RESUMO}

A resiliência financeira governamental é caracterizada pela forma com que entidades governamentais enfrentam e se recuperam de crises ou choques financeiros, sendo manifestada a partir de dimensões interativas. Frente ao choque gerado pela COVID-19, a presente pesquisa busca avaliar se a vulnerabilidade e a capacidade de antecipação (proxies de resiliência) possuem correlação com a capacidade de enfrentamento ao vírus (mensurado pela quantidade de testes por habitante). Para determinar as possíveis correlações, foi utilizado o teste de correlação de Spearman, visto que a amostra não respeitava a normalidade na sua distribuição, para medir o relacionamento entre as variáveis. As evidências apontam correlação negativa entre a dependência de transferência intergovernamental (vulnerabilidade) e a capacidade de geração de poupança (capacidade de antecipação) e a capacidade de enfrentamento à COVID-19. Apesar das limitações metodológicas, a pesquisa fornece uma potencial contribuição no avanço da observação da interação entre os aspectos financeiros e sociais da resiliência, principalmente tendo em vista o papel que a contabilidade exerce em moldar diferentes formas e caminhos para a resiliência financeira governamental, proporcionando respostas de curto ou longo prazo aos choques, antecipando-os através de mecanismos de planejamento e controle, o que pode contribuir para o desenvolvimento de práticas de governança baseadas nesta literatura.

Palavras-chave: Resiliência. Choques. COVID-19. 


\begin{abstract}
Governmental financial resilience is characterized by the way in which government entities face and recover from financial crises or shocks, being manifested from interactive dimensions. In view of the shock generated by COVID-19, the present research seeks to assess whether vulnerability and the ability to anticipate (resilience proxies) are correlated with the ability to cope with the virus (measured by the number of tests per inhabitant). To determine possible correlations, Spearman's correlation test was used, since the sample did not respect normality in its distribution, to measure the relationship between variables. The evidence points to a negative correlation between the dependence on intergovernmental transfer (vulnerability) and the ability to generate savings (anticipation capacity) and the capacity to cope with COVID-19. Despite methodological limitations, the research provides a potential contribution to advancing the observation of the interaction between the financial and social aspects of resilience, especially in view of the role that accounting plays in shaping different forms and paths for government financial resilience, providing answers short- or long-term shocks, anticipating them through planning and control mechanisms, which can contribute to the development of governance practices based on this literature.
\end{abstract}

Keywords: Resilience. Shocks. COVID-19.

\title{
1 INTRODUÇÃO
}

Crises e choques financeiros não são acontecimentos estranhos aos governos. Recentemente, a exemplo, esses governos foram desafiados pela crise de 2008 , que se iniciou com uma espécie de inadimplência coletiva no setor bancário nos Estados Unidos, e repercutiu pelos mercados financeiros ao redor do mundo, desencadeando uma crise internacional (BARBERA et al., 2017). Aproximadamente 12 anos após a crise financeira de 2008, a economia mundial encontra-se caminhando para uma nova recessão, em decorrência da COVID-19.

A pandemia da COVID-19, apesar de ser uma crise de ordem sanitária, também instaura na sociedade uma crise econômica. Como uma das formas de propagação do vírus é o contato humano, a Organização Mundial de Saúde (OMS) orientou que o melhor nesse momento é o isolamento social, o que impede o normal funcionamento de empresas de diversos setores. Isso fez com que, à medida que foram se confirmando casos em diversos países, houvesse um convulsonamento no mercado financeiro nacional, com posterior transbordamento negativo em demais centros financeiros regionais e fazendo com que o medo se transformasse em um ciclo vicioso de desaceleração econômica global (SENHORAS, 2020).

Embora esses eventos sejam descritos como únicos e sem soluções imediatas (BOIN; LODGE, 2016), observa-se que eles estão cada vez mais presentes na rotina das organizações públicas, exigindo habilidades para lidar com declínios financeiros e instabilidades econômicas, seja identificando os sinais de crise de maneira antecipada, seja enfrentando-os quando estes impactos atingem as finanças do governo e sociedade (BATISTA; CRUZ, 2019). Surge, portanto, a ideia de resiliência financeira (LINO, 2019).

Pela sua amplitude, a resiliência financeira não tem uma única definição, sendo normalmente retratada como resultado de uma variedade de dimensões (BARBERA et al., 2017; LIMA; AQUINO, 2019). Resumindo o que há de comum, Barbera et al. (2017) e Raasch, Martins e Gomes (2018) afirmam que a resiliência se trata de a capacidade da organização 
diminuir riscos, se adaptar rapidamente a um choque e permanecer operando em condições adversas, tais como crises econômicas ou desastres ambientais. Nesse sentido, entende-se que organizações resilientes são aquelas que lidam melhor com crises e se recuperam mais rapidamente de choques.

No contexto das organizações públicas, Barbera et al. (2017) indica que quando esses choques ou crises afetam as finanças de governos, a forma com que essas organizações reagem e se recuperam é chamada de resiliência financeira governamental. Essa característica se manifesta por dimensões internas e externas, dentre as quais estão: (i) a vulnerabilidade (nível de exposição a um choque), (ii) capacidade de antecipação (ferramentas e recursos para melhor identificar suas vulnerabilidades) e (iii) a capacidade de enfrentamento (habilidade de enfrentar os choques, seja amortecendo os efeitos, implementando mudanças incrementais ou radicais) (BARBERA et al., 2017; BATISTA; CRUZ, 2019), essa havendo uma interação entre todas elas (LIMA; AQUINO, 2019).

De forma mais ampla, na última década, tanto a literatura acadêmica quanto a comunidade internacional passaram a discutir cada vez mais essas dimensões de resiliência em governos (LINO, 2019). Para a comunidade acadêmica, compreendê-las pode ajudar as organizações públicas a planejar e lidar com um futuro incerto (BARBERA et al., 2017), mas, além disso, destaca Lino (2019), entendê-las é vital para a continuidade dos serviços e para manter a qualidade de vida dos cidadãos que integram uma comunidade específica incitando a própria comunidade a discutir sobre resiliência combinando aspectos sociais e financeiros.

Mesmo com os avanços consideráveis na literatura, muito ainda pode ser explorado. Isso porque, apesar do apelo realizado por Lino (2019), ainda existe um viés de interpretação voltado apenas para os aspectos financeiros. Exemplo disso, são as recentes discussões que abordaram a crise financeira de 2007 - 2008, como as pesquisas disponíveis em Governmental Financial Resilience: International Perspectives on how Local Governments face Austerity. Em síntese, Batista e Cruz (2019) observaram que os estudos discutiram a resiliência financeira governamental de duas maneiras: (i) majoritariamente com abordagem qualitativa, por meio de estudos de caso múltiplos, a fim de identificar diferentes padrões de resiliência financeira e (ii) minoritariamente, com uma abordagem quantitativa, tendo sido escolhido indicadores fiscais e socioeconômicos como proxies das dimensões da resiliência financeira governamental.

Diante do contexto, considerando a pandemia da COVID-19, em conjunto aos chamados recentes pela comunidade acadêmica, este estudo pretende - dentro do contexto da expansão tanto das práticas quanto dos estudos em resiliência - preencher uma lacuna na literatura ao avaliar a associação entre a vulnerabilidade e a capacidade de antecipação com a capacidade de enfrentamento à COVID-19 pelos estados brasileiros.

Como já se prevê os impactos negativos nas finanças governamentais, caracterizado, por exemplo, pela provável queda da arrecadação tributária, logo, para o melhor enfrentamento da pandemia da COVID-19, além da adoção das medidas recomendadas pelas autoridades sanitárias, é necessário que os entes públicos, dentre outras atitudes cabíveis, tenham mantido satisfatórios padrões de resiliência para suportar este choque financeiro sem afetar sua capacidade de regular entrega de serviços públicos à população. Portanto, o melhor conhecimento de fatores associados a esta capacidade de enfrentamento traz contribuições práticas aos entes governamentais, à medida que servem de subsídio para a estruturação e desenho dos mecanismos de governança necessários para o bom enfrentamento de possíveis futuras crises. 
Lucas Candeia Martins, Thiago Vitor Ferreira Soares, Paulyane Gomes da Silva e Amanda Braz da Silva

\section{REFERENCIAL TEÓRICO}

Os governos sempre tiveram que lidar com declínios financeiros e instabilidades econômicas, seja identificando os sinais de crise ou choques financeiros de maneira antecipada, seja enfrentando-os quando os impactos atingem finanças do governo e sociedade (BATISTA; CRUZ, 2019). Segundo Lino (2019) ainda que crises e choques financeiros sejam frequentemente retratados como eventos únicos, eles estão se tornando cada vez mais rotineiros, exigindo que os governos estejam constantemente prontos para lidar com eles.

Apresentando descrições intimamente associadas, Boin e Lodge (2016) destacam que as crises não possuem soluções imediatas, não respeitam prazos e tendem a ser dinâmicas e caóticas por natureza, assim como os choques financeiros, que representam quaisquer eventos externos ou internos inesperados, que tenham impactos significativos e duradouros nas finanças de uma organização, afetando negativamente sua posição financeira e ameaçando sua sobrevivência (BARBERA et al., 2017; SALITERER; JONES; STECCOLINI, 2017).

Para lidar com os efeitos das crises, os governos locais de diferentes países adotaram estratégias direcionadas para antecipar, absorver e reagir aos choques que afetam suas finanças ao longo do tempo (BATISTA; CRUZ, 2019; LINO, 2019). Nesse contexto, surge a ideia de resiliência financeira (LINO, 2019). Conforme Hood (1991), que realizou o estudo seminal sobre o tema, o conceito de resiliência financeira envolve a capacidade de reduzir riscos e de se adaptar rapidamente a um choque e continuar operando. Em uma perspectiva organizacional, Lima e Aquino (2019) indicam que as organizações resilientes podem desenvolver novas capacidades e habilidades para explorar as oportunidades que surgem. Entendida sobre essas perspectivas, "a resiliência financeira se apresenta como vital para a continuidade de serviços públicos e, mais do que isso, para manter a qualidade de vida dos cidadãos que integram uma comunidade específica" (LINO, 2019, p. 3).

Apesar da importância dos debates sobre o tema, a sua ampla discussão só se deu na última década, devido os impactos da mais recente crise econômica mundial (BARBERA et al., 2017; BARBERA; GUARINI; STECCOLINI, 2020). Segundo Batista e Cruz (2019) e Barbera, Guarini e Steccolini (2020), no meio acadêmico, os impactos e as respostas governamentais à crise se tornaram objetos de estudo, enquanto no meio profissional passaram a ser objetos de discussão entre associações, como por exemplo, no Instituto de Finanças Públicas e Contabilidade (Chartered Institute of Public Finance and Accountancy-CIPFA). Além disso, foi intensificado o apelo para que se desenvolvessem pesquisas com foco nas capacidades de antecipação e habilidades dos governos em lidar com crises (BOIN; LODGE, 2016), isso porque a magnitude dos choques financeiros pode ser potencializada pelo nível de vulnerabilidade (BATISTA; CRUZ, 2019).

Ainda com Batista e Cruz (2019), a vulnerabilidade é interpretada como o nível de exposição a um choque específico. Para Barbera et al. (2017) e Saliterer, Jones e Steccolini (2017), uma série de fatores externos e internos contribui para o nível de exposição, inclusive a dependência ou a incerteza das receitas, a rigidez das despesas, as imprecisões ou reduções de recursos de transferências governamentais, o nível de endividamento, além do grau de diversificação das fontes de receita. Desse modo, Batista e Cruz (2019) tratam que as vulnerabilidades precisam ser identificadas a fim de que se desenvolvam ações voltadas ao tratamento de fragilidades ou à adequação ao controle de fatores externos, com vistas à identificação dos choques antes mesmo que ocorram.

Mesmo com os avanços consideráveis na literatura, uma recorrente discussão é o que forma ou gera um padrão de resiliência financeira, ou seus aspectos específicos (LIMA; AQUINO, 2019). Para Steccolini, Jones e Saliterer (2017), os estudos publicados sugerem que 
não existe uma abordagem única para a resiliência e que os governos escolhem qual estratégia de resiliência seguirão com base em suas capacidades e na maneira como percebem sua vulnerabilidade diante de uma crise. Desse modo, Barbera et al. (2017) observou que a resiliência é vista como uma combinação dinâmica de dimensões interrelacionadas, que são: (i) pressões externas (com impactos financeiros), (ii) vulnerabilidade (percebida), (iii) capacidade antecipatória dos governos e (iv) capacidade de enfrentamento à pressão.

A partir da análise de governos locais de diferentes países e dos fatores que moldam a habilidade de lidar com crises, Barbera et al. (2017) propuseram um framework descrevendo os padrões de resiliência. Indutivamente, foram propostos cinco padrões de resiliência financeira: autorregulados (self-regulartos), adaptados-restritos (constrained adapters), adaptados-reativos (reactive adapters), fatalistas-arrogantes (contented fatalists) e fatalistasabnegados (powerless fatalists). Tais padrões resultam da interação das condições organizacionais que ao longo do tempo emergem das vulnerabilidades da organização e das respostas elaboradas para assimilar as pressões financeiras (BARBERA et al., 2017).

À luz das considerações anteriores, estudos foram realizados em governos locais de diversos países, caracterizados por sistemas administrativos próprios, bem como estratégias de respostas diferentes frente à crise econômica iniciada em 2008 (Quadro 01). Segundo Lodge e Hood (2012) e Steccolini, Jones e Saliterer (2017), países de todo o mundo foram afetados por esta crise financeira de diferentes formas - alguns sendo afetados imediatamente e/ou substancialmente mais do que outros - e, portanto, também responderam aos desafios relacionados de maneiras distintas. A este respeito, as políticas definidas pelos governos locais, incluindo arranjos fiscais, a saber: estrutura, base e o controle das fontes de receita, regras de dívida, diretrizes de investimento, sistema de monitoramento e limites fiscais, parecem ter influenciado não apenas o impacto, mas também a gama de possíveis respostas fiscais frente à crise (STECCOLINI; JONES; SALITERER, 2017).

Quadro 01 - Pesquisas anteriores sobre Resiliência Financeira em governos locais

\begin{tabular}{|l|l|l|}
\hline Autor(es) & Principais estratégia(s)/resposta(s) à crise & País(es) \\
\hline $\begin{array}{l}\text { Aquino e Cardoso (2017), Barbera } \\
\text { (2017), Cohen e Hlepas (2017), Drew } \\
\text { (2017), Du Boys (2017), Jones (2017), } \\
\text { Korac, Saliterer e Scorsone (2017) e } \\
\text { Overmans (2017) }\end{array}$ & $\begin{array}{l}\text { Governos locais tiveram que lidar com } \\
\text { cortes ou atrasos intencionais de } \\
\text { transferências/subvenções dos governos } \\
\text { nacionais }\end{array}$ & $\begin{array}{l}\text { Austrália, Brasil, } \\
\text { Estados Unidos, França, } \\
\text { Grécia, Holanda, } \\
\text { Inglaterra e Itália }\end{array}$ \\
\hline $\begin{array}{l}\text { Aquino e Cardoso (2017), Drew } \\
\text { (2017), Du Boys (2017) e Papenfuß, } \\
\text { Saliterer e Albrecht (2017) }\end{array}$ & $\begin{array}{l}\text { Redução dos limites dos impostos ou } \\
\text { remoção de impostos exigidos pelos } \\
\text { governos nacionais ou subnacionais }\end{array}$ & $\begin{array}{l}\text { Alemanha, Austrália, } \\
\text { Brasil, França e Itália }\end{array}$ \\
\hline $\begin{array}{l}\text { Barbera (2017), Jones (2017), Korac } \\
\text { (2017) e Overmans (2017) }\end{array}$ & $\begin{array}{l}\text { Transferência dos serviços prestados pelos } \\
\text { governos nacionais e subnacionais para os } \\
\text { governos locais com suporte financeiro }\end{array}$ & $\begin{array}{l}\text { Áustria, Holanda, Itália } \\
\text { e Inglaterra }\end{array}$ \\
\hline $\begin{array}{l}\text { Cohen e Hlepas (2017), Drew (2017), } \\
\text { Du Boys (2017), Jones (2017) e } \\
\text { Overmans (2017) }\end{array}$ & $\begin{array}{l}\text { Alteração de regulamentos ou diretrizes } \\
\text { para promover a institucionalização de } \\
\text { capacidades mais fortes, equipando melhor } \\
\text { os governos locais para antecipar ou lidar } \\
\text { com choques }\end{array}$ & $\begin{array}{l}\text { Austrália, França, } \\
\text { Inglaterra, Holanda e }\end{array}$ \\
\hline
\end{tabular}

Nota(s): foi identificado um estudo realizado nos governos locais suecos, no entanto, as capacidades de antecipação e enfretamento - que mantiveram as finanças suecas estáveis -, foram alcançadas antes mesmo da crise de 2008/09 e não por causa dela (ver Wällstedt e Almqvist, 2017).

Fonte: elaborado pelos autores a partir de Steccolini, Jones e Saliterer (2017). 
Em geral, as recentes discussões abordaram que a reação às pressões que afetaram suas finanças se concentra em cortes orçamentários (Quadro 01). Segundo Steccolini, Jones e Saliterer (2017), muitas vezes não é decisão do governo local cortar o orçamento, mas sim de uma política do governo central, impondo cortes e atrasos no envio de verbas. Embora a política top-down exerça pressão na realização de despesas no nível local, contribuindo para o enxugamento dos gastos públicos e o enfrentamento dos impactos gerados pelos choques financeiros, Lino (2019) observa que isso se torna preocupante em governos locais que tem muita dependência de transferências federais, pois (i) os serviços prestados à sociedade podem ser suspensos ou, em outros casos, (ii) os governos não reduzem seus gastos, se endividando e esperando por ajuda através de transferências do governo central. Ainda segundo Lino (2019), sob um olhar meramente financeiro, sem levar em conta os anseios e necessidades dos cidadãos, algumas estratégias podem ser positivas para os cofres públicos, porém, aumentar a pobreza e estagnar uma parcela da população nesta situação, pode criar estresses crônicos que se transformarão em pressões no longo prazo. Assim, nenhum dos dois caminhos é salutar em termos de resiliência financeira (LINO, 2019).

Nesta perspectiva, aspectos relacionados à capacidade transformativa, ou seja, a capacidade de implementar mudanças radicais, abrangendo estruturas, funções, objetivos e valores, são vistas como menos nocivas para a prestação de serviços públicos no curto prazo e na manutenção da saúde financeira dos governos locais no longo prazo (BARBERA et al., 2017; LINO, 2019). Apesar de reconhecer que as capacidades de enfrentamento da crise se manifestam desde o simples buffer até estratégias mais transformadoras, a maior parte das respostas já encontradas empiricamente refere-se ao primeiro grupo (STECCOLINI; JONES; SALITERER, 2017; LINO, 2019).

Sustentando-se na literatura, ao verificar um foco demasiado sobre a questão financeira, com pouca preponderância ou centralidade nas funções vitais do governo e seu impacto na prestação de serviços (LINO, 2019), em conjunto com as recentes medidas recomendadas pelas autoridades sanitárias para o melhor enfrentamento da pandemia da COVID-19, que requer, dentre outras atitudes cabíveis, padrões satisfatórios de resiliência para suportar o choque financeiro sem afetar sua capacidade de regular a entrega de serviços públicos à sociedade, esta pesquisa preenche uma lacuna ao propor avaliar se a vulnerabilidade e a capacidade de antecipação de entes governamentais possuem associação com a capacidade de enfrentamento à crise da COVID-19, sendo esta vista de maneira não financeira, mas combinando aspectos sociais e financeiros do conceito de resiliência.

\section{METODOLOGIA}

A população alvo da pesquisa compreende os 27 estados brasileiros, entes federativos dotados de autonomia financeira, política e administrativa, sendo competente de forma concorrente à união e municípios por legislar sobre proteção e defesa da saúde (BRASIL, 1988). A escolha desses entes federativos é justificada pelas suas competências no estabelecimento de medidas para o enfrentamento da COVID-19 no Brasil, como a responsabilidade por implantação de unidades de saúde temporária (hospitais de campanha) e a capacidade de adotar medidas que julguem necessários para frear a disseminação do vírus, como determinação de isolamento social ou fechamento do comércio.

A fim de verificar se a capacidade de antecipação e as vulnerabilidades financeiras dos estados brasileiros têm associação com o enfrentamento da COVID-19, foram utilizadas as proxies desenvolvidas por Batista e Cruz (2019) para as primeiras dimensões.

Em relação à capacidade de enfrentamento, foi desenvolvida proxy para representá-la 
neste estudo. Para o melhor enfrentamento da pandemia da COVID-19, é necessário que os governos reforcem a capacidade do sistema de saúde pública local, o que inclui maciços investimentos de recursos para aquisição de insumos básicos, desenvolvimento e aquisição de testes, remédios e equipamentos, além da contratação e treinamento de pessoal para realizar os atendimentos à população (KROTH, 2020).

Quanto aos testes, o diretor da OMS, Tedros Adhanom Ghebreyesu, em reunião no dia 16/03/2020, fez um apelo para que todos os países apliquem testes em massa para que haja maior identificação dos contaminados, o que possibilita isolá-los, impedindo que estes contaminem outras pessoas. Segundo Tedros, não se vê uma escalada suficientemente urgente de testes, isolamento e rastreamento de contato, que é a espinha dorsal da resposta à COVID-19 (CNBC, 2020). Portanto, levou-se em consideração a importância de se aplicar testes na população para definir esta métrica como proxy da melhor capacidade de enfrentamento à crise causada pelo COVID-19 pelos estados brasileiros. A Tabela 1 resume as variáveis utilizadas no estudo.

Tabela 1 - Resumo das variáveis

\begin{tabular}{|c|c|c|}
\hline Variável & $\mathrm{O}$ que mensura & Cálculo \\
\hline \multicolumn{3}{|c|}{ (1) Capacidade de Enfrentamento } \\
\hline TesteHab ${ }^{(1)}$ & $\begin{array}{l}\text { Quantidade de testes por } \\
\text { habitantes }\end{array}$ & Quantidade de testes aplicados $\div$ Habitantes \\
\hline \multicolumn{3}{|c|}{ (2) Vulnerabilidade } \\
\hline $\operatorname{RigOrc}^{(2)}$ & Grau de rigidez orçamentária & $\begin{array}{l}\text { Despesa total com pessoal } \div \text { Receita corrente } \\
\text { líquida }\end{array}$ \\
\hline Transf ${ }^{(3)}$ & $\begin{array}{l}\text { Dependência de transferências } \\
\text { intergovernamentais }\end{array}$ & Transferências correntes $\div$ Receitas correntes \\
\hline End $^{(4)}$ & Grau de endividamento do Estado & Dívida consolidada $\div$ Receita corrente líquida \\
\hline
\end{tabular}

(3) Antecipação

\begin{tabular}{lll}
\hline $\operatorname{CGPP}^{(5)}$ & $\begin{array}{l}\text { Capacidade de geração de } \\
\text { poupança }\end{array}$ & $\begin{array}{l}\text { (Receita corrente - Despesa corrente) } \div \text { Receita } \\
\text { corrente }\end{array}$ \\
\hline
\end{tabular}

Legenda(s): (1) TesteHab: Teste por habitantes; (2) RigOrc: Rigidez orçamentária; (3) Transf: Transferência; (4) End: Endividamento; e (5) CGPP: Capacidade de antecipação - poupança.

Fonte: elaborada pelos autores a partir de Batista e Cruz (2019).

Os dados das variáveis que representam a vulnerabilidade e a capacidade de antecipação são referentes ao exercício de 2019 e foram coletados no Sistema de Informações Contábeis e Fiscais (SICONFI). A variável de teste por habitantes (capacidade de enfrentamento) foi construída a partir do quociente entre testes aplicados pelo número de habitantes do estado. Os dados foram coletados no banco de dados organizado pelo Ministério da Saúde para dar transparência aos gastos com o combate à COVID-19. e são referentes à quantidade de testes aplicados até o dia 20/05/2020, quando se passaram 84 dias após o primeiro caso registrado no Brasil.

A fim de alcançar o objetivo da pesquisa, foi utilizado teste de correlação para mensurar a associação entre as variáveis selecionadas. Dentre os diversos existentes, o teste de correlação mais apropriado foi escolhido após verificação de que a amostra era composta por dados não paramétricos a partir do teste de normalidade de Kolmogorov-Smirnov (27, p $<0,05)$, cuja significância indica falta de distribuição normal dos dados. A partir desta constatação, foi selecionado o teste de correlação de Spearman bicaudal, por ser adequado para estes casos de falta normalidade na distribuição na amostra. Bicaudal por não haver 
Lucas Candeia Martins, Thiago Vitor Ferreira Soares, Paulyane Gomes da Silva e Amanda Braz da Silva

previsão do relacionamento das variáveis, dado o caráter exploratório do estudo (FIELD, 2009).

\section{RESULTADOS E DISCUSSÃO}

Para melhor contextualizar os resultados que atingem o objetivo da pesquisa, que é avaliar a associação entre a vulnerabilidade e a capacidade de antecipação com a capacidade de enfrentamento à COVID-19 pelos estados brasileiros, inicialmente foram realizadas análises descritivas das variáveis utilizadas. A análise preliminar foi realizada considerando a distribuição por região (Tabela 2).

Tabela 2 - Média das variáveis por região

\begin{tabular}{lccccc}
\hline Região & $\begin{array}{c}\text { Número de } \\
\text { Testes por } \\
\text { Habitantes }\end{array}$ & $\begin{array}{c}\text { Grau de } \\
\text { Rigidez } \\
\text { Orçamentária }\end{array}$ & $\begin{array}{c}\text { Dependência de } \\
\text { Transferências } \\
\text { Intergovernamentais }\end{array}$ & $\begin{array}{c}\text { Grau de } \\
\text { Endividamento }\end{array}$ & $\begin{array}{c}\text { Capacidade de } \\
\text { Geração de } \\
\text { Poupança }\end{array}$ \\
\hline Centro-oeste & 0,024 & 0,470 & 0,349 & 0,461 & 0,298 \\
Nordeste & 0,024 & 0,469 & 0,390 & 0,648 & 0,080 \\
Norte & 0,025 & 0,486 & 0,205 & 0,607 & 0,082 \\
Sudeste & 0,026 & 0,460 & 0,107 & 2,064 & 0,060 \\
Sul & 0,029 & 0,453 & 0,177 & 1,343 & 0,059 \\
\hline
\end{tabular}

Fonte: elaborada pelos autores, com base nos dados da pesquisa (2020).

Conforme consta na Tabela 2, é possível observar que a região Sul apresenta a melhor capacidade de enfrentamento, que é medida pelo número de testes por habitantes. Diferentemente do que foi demonstrado em relação ao relacionamento das dimensões da resiliência financeira governamental, a região não necessariamente demonstra os melhores indicadores que representam as dimensões da capacidade de antecipação e vulnerabilidades, como pode ser visto nas variáveis que tratam do grau de rigidez orçamentária, grau de endividamento (ficando atrás apenas da região Sudeste) e capacidade de geração de poupança. Supostamente, a região Sudeste, que se apresenta como a segunda região que mais testou seus habitantes, apresenta uma similaridade muito forte à região Sul, se tratando das capacidades de antecipação e vulnerabilidades.

Além disso, é possível observar na Tabela 02, em relação às demais regiões, Norte, Nordeste e Centro-Oeste, uma proximidade muito grande no número de testes por habitantes. Confirmando o achado anterior, é possível inferir que a condução dos serviços prestados à sociedade, como é o caso da testagem por habitantes, podem indicar a realização de práticas semelhantes de gestão, bem como a adoção de práticas comuns de resiliência.

A fim de construir um diagnóstico mais amplo, a Tabela 03 apresenta as estatísticas descritivas das variáveis em conjunto.

Tabela 3 - Estatísticas descritivas das variáveis

\begin{tabular}{llll}
\hline \multicolumn{1}{c}{ Variável } & Média & Mínimo & Máximo \\
\hline (1) Capacidade de enfrentamento & & & 0,043 \\
\hline TesteHab & 0,024 & 0,017 & \\
\hline (2) Vulnerabilidade & & & 0,606 \\
\hline RigOrc & 0,473 & 0,363 & 0,649 \\
Transf & 0,345 & 0,057 & 2,849 \\
End & 0,853 & 0,199 & \\
\hline (3) Capacidade de Antecipação & & & 0,697 \\
\hline CGPP & 0,126 & $-0,028$ & \\
\hline
\end{tabular}

Fonte: elaborada pelos autores, com base nos dados da pesquisa (2020). 
As estatísticas descritivas das variáveis revelam que apenas $2,4 \%$ da população brasileira havia sido testada para a COVID-19 até o dia 20/05/2020. Além disso, em relação às proxies para a dimensão vulnerabilidade, quanto às máximas, pode-se perceber que a amostra abrange estados com alto nível de rigidez orçamentária, chegando a ter aproximadamente $60 \%$ da sua receita corrente líquida comprometida com despesas com pessoal, altamente dependentes de transferências intergovernamentais e com grande nível de endividamento. Acerca da capacidade de antecipação, representada pela capacidade de geração de poupança, a média indica que há uma pequena folga de recursos financeiros correntes, chegando a ser deficitário em alguns casos. Levando em consideração que os dados são referentes ao exercício 2019, possivelmente essas características comprometeram a capacidade de enfrentamento à eminente crise causada pela COVID-19.

No entanto, essa conclusão só é possível com a verificação da associação entre estas variáveis. O resultado do teste de correlação entre as variáveis que representam a capacidade de antecipação, vulnerabilidades e capacidade de enfrentamento à COVID-19 é apresentado na Tabela 4.

Tabela 4 - Resultado do teste de correlação de Spearman

\begin{tabular}{llccccc}
\hline & & TesteHab & RigOrc & Transf & End & CGP \\
\hline \multirow{3}{*}{ TesteHab } & Coeficiente de correlação & 1,000 & $-0,228$ & $-0,633^{* * *}$ & 0,282 & $-0,390^{* *}$ \\
& Sig. (2 extremidades) & & 0,253 & 0,000 & 0,155 & 0,044 \\
& N & 27 & 27 & 27 & 27 & 27 \\
\hline
\end{tabular}

Legenda(s): *Correlação é significativa no nível 0,$10 ;{ }^{* *}$ significativa no nível 0,$05 ;{ }^{* * *}$ significativa no nível 0,01 . Fonte: elaborada pelos autores, com base nos dados da pesquisa (2020).

Apesar de ser impossível estabelecer relação de causa e efeito a partir desse teste, percebe-se que a capacidade de enfrentamento dos estados brasileiros à crise da COVID-19 possui forte correlação negativa estatisticamente significativa com a dependência de transferências intergovernamentais. A correlação negativa significa que quanto menor a dependência de transferências, maior a capacidade de enfrentamento, ou seja, da capacidade de testar a população. A maior dependência de transferência significa que o ente que a recebe não possui base tributária suficiente para arrecadar receitas próprias que supram a necessidade de serviços públicos pela população. Logo, precisam contar com o apoio financeiro e orçamentário de outras esferas governamentais (ARAÚJO et al., 2020). Tal dependência afeta sua capacidade de adoção de estratégias para enfrentar crises (AQUINO; CARDOSO, 2017), corroborando os achados aqui apresentados, que demonstram que entes com menor dependência destas transferências, que possuem em sua composição da receita corrente total, maior percentual de receitas próprias, conseguiram enfrentar a COVID-19 de forma mais eficiente.

No caso analisado, a crise da COVID-19, a dependência de transferências afeta a capacidade de aplicação de testes para detectar a doença na população. No entanto, os testes são menos onerosos que outras medidas necessárias para o enfrentamento dessa crise, como, por exemplo, a instalação e manutenção de hospitais de campanha, que, dada a associação encontrada, possivelmente são afetadas por esta dependência de transferências.

Quanto à capacidade de geração de poupança, proxy para a capacidade de antecipação, percebe-se que há moderada correlação negativa estatisticamente significativa. Esse resultado indica que os estados com menor capacidade de geração de poupança possuem maior capacidade de enfrentamento à COVID-19. Batista e Cruz (2019) encontram a mesma associação entre a capacidade de antecipação e enfrentamento, sendo esta medida 
pela variação das receitas próprias. Segundo os autores, a poupança gerada pelos estados em anos anteriores faz com que os governos se esforcem menos para arrecadar recursos próprios. No cenário ora analisado, é possível que os estados, ao perceberem que iriam gerar certo nível de poupança, tenham elaborado orçamentos mais rígidos para o exercício de 2020 e, com isso, diminuído a capacidade de aquisição de insumos básicos para o melhor controle da COVID-19, explicando o porquê estados com menor capacidade de geração de poupança foram aqueles que mais testaram sua população.

Nesta assertiva, a capacidade de antecipação e vulnerabilidades possuem associação com a forma com que os estados brasileiros enfrentaram, inicialmente, o choque causado pela COVID-19. Esse resultado é coerente com boa parte da recente literatura do tema, que reporta que as estratégias de enfrentamento às crises pelos governos têm associação com a sua capacidade de antecipação e vulnerabilidades percebidas (BATISTA; CRUZ, 2019; BARBERA et al., 2019).

Diferentemente dessas pesquisas, a associação encontrada no presente estudo demonstra que a capacidade de antecipação e vulnerabilidades não explicam apenas que tipo de medidas os governos locais adotam ao enfrentar choques ou crises, mas também a sua capacidade de adotar medidas altamente recomendadas para que os efeitos negativos de uma crise sejam mitigados, como é o caso da recomendação de aquisição e aplicação de testes para detecção da COVID-19. De maneira mais ampla, também é coerente com a ideia proposta por Barbera et al. (2017), em seu framework, de que as dimensões da resiliência financeira governamental são relacionadas entre si de forma dinâmica.

Conforme afirmam Barbera et al. (2017), a manutenção de bons padrões de resiliência financeira governamental a longo prazo exige que os governos construam longos processos, melhorando suas capacidades organizacionais, a forma como se antecipa aos choques e a percepção de suas vulnerabilidades. Por exemplo, com esse objetivo, governos podem estabelecer reservas fiscais obrigatórias, perseguir políticas de autonomia fiscal e buscar diversificação das fontes de receitas.

Desse modo, os resultados dispostos representam uma potencial contribuição, em especial aos estados brasileiros, aos quais fica a lição de reforçar o compromisso com a disciplina fiscal e baixos níveis de endividamento, que podem ajudar no desenvolvimento de habilidades para amortecer impactos de crises como a da COVID-19. Em particular, evitar déficits na ausência de crises e manter o devido equilíbrio orçamentário pode fornecer aos governos reservas que podem ser usadas quando do surgimento de uma crise repentina.

\section{CONSIDERAÇÕES FINAIS}

O principal objetivo desta pesquisa foi verificar, com uma abordagem quantitativa, se existe associação entre a capacidade de antecipação, vulnerabilidades e capacidade de enfrentamento à COVID-19 pelos estados brasileiros.

Para isto, foram utilizadas proxies apresentadas por Batista e Cruz (2019) para as dimensões de capacidade de antecipação e vulnerabilidade. Em relação à capacidade de enfrentamento, esta foi representada pela quantidade de testes per capita para o COVID-19 aplicados pelo sistema público de saúde destes estados. A escolha foi justificada pelas recorrentes afirmações das autoridades sanitárias de que o ato de testar a população faz com que a cadeia de transmissão do vírus seja quebrada, já que há o rastreamento e isolamento dos infectados. Em última análise, a capacidade de teste é entendida como capacidade de enfrentamento à COVID-19. 
Os resultados sugerem que a dependência de transferências intergovernamentais (vulnerabilidade) e a capacidade de geração de poupança (antecipação) têm associação com a capacidade de enfrentamento à pandemia. Em relação às transferências, os estados com maior dependência possuem menor capacidade de aplicação de testes, enquanto os estados com maior capacidade de geração de poupança possuem menor capacidade de testes, o que é atribuído ao aumento da rigidez do orçamento mediante a folga financeira gerada pela poupança.

Apesar de a metodologia adotada possuir diversas limitações, como o fato de ignorar que a resiliência é um fenômeno dinâmico, tendo a necessidade de analisá-lo de forma longitudinal (BATISTA; CRUZ, 2019), acredita-se que as evidências apontadas nos resultados do estudo sejam suficientes para reforçar a necessidade de constante observação da interação entre os aspectos financeiros e sociais da resiliência. Ainda, os achados constituem contribuições teóricas, metodológicas e práticas. Teóricas porque acrescenta ao corpo de conhecimento sobre o tema evidências quantitativas da associação entre as dimensões da resiliência financeira governamental auxiliando o conhecimento acerca dos fatores que impactam na capacidade de enfrentamento aos choques. Além disto, atendemos ao chamado da literatura de maior interação entre fatores financeiros e sociais em pesquisa sobre resiliência governamental (LINO, 2019), o que fazemos ao verificar de que forma fatores financeiros impactam na capacidade de adoção de medidas sanitárias por entes públicos. Metodológicas ao propor a utilização de proxies para a capacidade de enfrentamento ainda não utilizadas pela literatura do tema.

Práticas por demonstrar que há a necessidade de desenvolvimento de práticas de governança baseadas na ideia de buscar bons padrões de resiliência. Neste sentido, retomase o papel que a contabilidade exerce em moldar diferentes formas e caminhos para a resiliência financeira governamental, proporcionando respostas de curto ou longo prazo aos choques, antecipando-os através de mecanismos de planejamento e controle (BARBERA; GUARINI; STECCOLINI, 2020) o que, em suma, demonstra a importância destes profissionais não apenas no enfrentamento da crise causada pela pandemia da COVID-19, mas também na reorganização da sociedade no período pós pandemia.

Por fim, como sugestão de pesquisas futuras que surgem a partir desta, recomenda-se a verificação da relação entre as dimensões da resiliência financeira governamental com a capacidade de adoção de outras estratégias ao enfrentamento da COVID-19, como por exemplo, instalação de hospitais de campanha, criação de novos leitos na unidade de terapia intensiva ou aquisição de outros insumos necessários para o diagnóstico e tratamento da doença. Além disto, diante da evidência de que as vulnerabilidades e a capacidade de antecipação possuem associação com a capacidade de enfrentamento à COVID-19, sugere-se a busca de outros fatores relacionados a esta capacidade, tais como, fatores políticopartidário, organizacionais e contingenciais.

\section{REFERÊNCIAS}

AQUINO, A.; CARDOSO, R. Financial resilience in Brazil in Municipalities. Governmental

Financial Resilience. Published online, v. 27, p. 53-71, 2017. http://dx.doi.org/10.1108/S2053-769720170000027004. 
Lucas Candeia Martins, Thiago Vitor Ferreira Soares, Paulyane Gomes da Silva e Amanda Braz da Silva

ARAÚJO, R. et al. A Relação da Natureza das Transferências Governamentais e a Responsabilidade Fiscal de Governos Municipais Brasileiros. Revista Contabilidade, Gestão e Governança, v. 23, n. 1, p. 124-140, 2020.

BARBERA, C. et al. Patterns of financial resilience in Italian Municipalities. Governmental Financial Resilience, v. 27, p. 153-171, 2017. https://doi.org/10.1108/S2053769720170000027009.

BARBERA, C.; GUARINI, E.; STECCOLINI, I. How do governments cope with austerity? The roles of accounting in shaping governmental financial resilience. Accounting, Auditing \& Accountability Journal, 2020.

BATISTA, A.; DA CRUZ, C. Resiliência financeira governamental: evidências nos estados brasileiros. Revista Cadernos de Finanças Públicas, Brasília, v. 19, n. 3, p. 1-67. 2019. Disponível em: https://publicacoes.tesouro.gov.br/index.php/cadernos/article/view/65/45. Acesso em: 10 maio 2020.

BOIN, A.; LODGE, M. Designing resilient institutions for transboundary crisis management: A time for public administration. Public Administration, v. 94, n. 2, p. 289-298, 2016. https://doi.org/10.1111/padm.12264.

COHEN, S.; HLEPAS, N. Financial resilience of Greek Local Governments. Governmental Financial Resilience, v. 27, p. 135-152, 2017. http://dx.doi.org/10.1108/S2053769720170000027008.

DREW, J. A tale of two jurisdictions: a focus on the effect of regulatory constraints on municipal resilience in Australia. Governmental Financial Resilience, v. 27, p. 35-52, 2017. https://doi.org/10.1108/S2053-769720170000027003.

DU BOYS, C. Resilience Patterns of French Municipalities: A Case Study. Governmental Financial Resilience. v. 27, p. 93-113, 2017. https://doi.org/10.1108/S2053769720170000027006.

FIELD, A. Descobrindo a Estatística Usando o SPSS-5. Penso Editora, 2009.

HOOD, C. A public management for all seasons? Public Administration, v. 69, p. 3-19, 1991. Disponível em:

https://eclass.uoa.gr/modules/document/file.php/PSPA108/4NMP\%20all\%20seasonsfulltext .pdf. Acesso em: 08 jun. 2020.

JONES, M. English Resilience in the Face of Austerity. Governmental Financial Resilience, v. 27, p. 73-91, 2017. https://doi.org/10.1108/S2053-769720170000027005.

KORAC, S. "Austria - Building Capacities Versus Resting on Laurels. Governmental Financial Resilience, v. 27, p. 17-33, 2017. https://doi.org/10.1108/S2053-769720170000027002. 
KORAC, S.; SALITERER, I.; SCORSONE, E. Financial Resilience at the Root of the Crisis Michigan, U.S. Governmental Financial Resilience, v. 27, p. 207-227, 2017. https://doi.org/10.1108/S2053-769720170000027012.

KROTH, D. A economia brasileira frente a pandemia do COVID-19: entre as prescrições e as propostas do governo. Estado, Sociedade e Políticas Públicas, 2020. DOI: 10.13140/RG.2.2.12914.66241.

LIMA, D.; AQUINO, A. Resiliência financeira de fundos de regimes próprios de previdência em municípios. Revista Contabilidade \& Finanças, v. 30, n. 81, p. 425-445, 2019. https://doi.org/10.1590/1808-057×201908810.

LINO, A. Resiliência Financeira: um debate sobre seus impactos reais. In: Encontro da Associação Nacional de Pós-Graduação e Pesquisa em Administração - EnANPAD, XLIII. Anais de Congresso, São Paulo, 2019. https://doi.org/10.1111/padm.12264.

LODGE, M.; HOOD, C. Into an age of multiple austerities? Public management and public service bargains across OECD countries. Governance: An International Journal of Policy, Administration, and Institutions, v. 25, n. 1, p. 79-101, 2012. DOI: 10.1111/j.14680491.2011.01557.x.

OVERMANS, T. Financial Resilience: How Dutch Cities Have Buffered and Adapted to the Financial Crisis. Governmental Financial Resilience, v. 27, p. 173-186, 2017. https://doi.org/10.1108/S2053-769720170000027010.

PAPENFUß, U.; SALITERER, I.; ALBRECHT, N. A Cushioned Impact of the Financial Crisis - Local Government Financial Resilience in Germany. Governmental Financial Resilience, v. 27, p. 115-134, 2017. http://dx.doi.org/10.1108/S2053-769720170000027007.

RAASCH, M.; SILVEIRA-MARTINS, E.; GOMES, C. Resiliência: uma Bibliometria em Bases de Dados Nacionais e Internacionais. Revista de Negócios, v. 22, n. 4, p. 40-55, 2018. DOI: http://dx.doi.org/10.7867/1980-4431.2017v22n4p40-55.

SALITERER, I.; JONES, M.; STECCOLINI, I. Introduction: Governments and Crises.

Governmental Financial Resilience, v. 27, p. 1-16, 2017. http://dx.doi.org/10.1108/S2053769720170000027001.

SENHORAS, E. Novo Coronavírus e seus impactos econômicos no mundo. Boletim de conjuntura (BOCA), v. 1, n. 2, p. 39-42, 2020. DOI:

http://dx.doi.org/10.5281/zenodo.3761708.

STECCOLINI, I.; JONES, M.; SALITERER, I. Conclusion. Governmental Financial Resilienc, v. 27, p. 229-240, 2017. https://doi.org/10.1108/S2053-769720170000027013.

WÄLLSTEDT, N.; ALMQVIST, R. Financial Resilience: The Swedish Case. Governmental Financial Resilience, v. 27, p. 187-205, 2017. http://dx.doi.org/10.1108/S2053-769720170000027011. 
Lucas Candeia Martins, Thiago Vitor Ferreira Soares, Paulyane Gomes da Silva e Amanda Braz da Silva

CNBC. World Health Organization says some nations aren't running enough coronavirus tests: 'Test every suspected case'. 2020. Disponível em: https://www.cnbc.com/2020/03/16/whosays-some-nations-arent-running-enough-coronavirus-tests-test-every-suspected-case.html. Acesso em: 20 maio 2020. 